\title{
O BRASIL COMO OBJETO DE ESTUDO NA PESQUISA SOBRE TURISMO NO CONTEXTO INTERNACIONAL
}

\begin{abstract}
BRAZIL AS OBJECT OF STUDY ON TOURISM IN THE INTERNATIONAL RESEARCH CONTEXT
\end{abstract}

\section{BRASIL COMO OBJETO DE ESTUDIO SOBRE EL TURISMO EN EL CONTEXTO DE INVESTIGACIÓN INTERNACIONAL}

Wesley Moreira Pinheiro

Doutorando em Administração pela ESPM-SP

Mestre em Administração pela PUC-SP

E-mail:wesleymp@gmail.com

George Bedinelli Rossi

Doutor em Administração pela FGV-SP

Mestre em Administração pela FGV-SP

E-mail: george@espm.br

Data de Submissão: 20/07/2015

Data de Aprovação: 15/10/2015

RESUMO: De 2000 a 2014 o volume de turistas internacionais cresceu 68\%, segundo dados da OMT. Os desdobramentos desse crescimento interessam tanto os estudos mercadológicos quanto os acadêmicos. O objetivo geral desse artigo é verificar como o Brasil figura nos estudos de publicações internacionais sobre Turismo, tendo como unidade amostral o Tourism Management. Com isso, é necessário discutir o papel do país no interesse investigativo da produção internacional, sendo ele o ator principal ou um elemento de contextualização. A metodologia utilizada nesse estudo concentra-se em uma meta-análise sobre o conteúdo de publicações em artigos publicados, a partir das variáveis e das técnicas analíticas dos estudos de Matos e Henrique (2006); Melo e Andreassi (2010); e Souza, Roglio, e Takahashi (2011). Como principal resultado dessa pesquisa, tem-se um indicador que o Brasil ainda é pouco explorado como objeto de estudo e muitas vezes é apenas citado em uma contextualização. Por fim, nas considerações finais discute-se o papel do Brasil no campo do Turismo e da Administração, propondo-se alguns problemas de pesquisa para provocar o interesse de pesquisadores brasileiros e 
estrangeiros sobre assuntos cujo país pode ser relevante às pesquisas, porém, ainda pouco explorado, especialmente no campo dos estudos internacionais de turismo.

Palavras-chave: Turismo no Brasil. Turismo internacional. Meta-análise.

ABSTRACT: From 2000 to 2014, the volume of international tourists increased by $68 \%$, according to data from the WTO. The implications of this growth are of interest both for market studies and for students. The overall aim of this article is to investigate how Brazil appears in studies of international publications on tourism, using Tourism Management as the sample. For this purpose, it discusses the role of the country as a focus of research interest of international production, whether as the main actor or an element of contextualization. The methodology used in this study focuses on a meta-analysis of the content of published articles, based on the variables and analytical techniques of the studies of Matos and Henrique (2006); Melo and Andreassi (2010); and Souza, Roglio, and Takahashi (2011). The main result of this research indicates that Brazil is still little explored as an object of study, and is often only mentioned in a wider context. In the final considerations, we discuss the role of Brazil in the field of Tourism and Administration, proposing some research problems to prompt interest among Brazilian and foreign researchers on subjects of potential relevance to the country that are still little explored, especially in the field of international tourism studies.

Keywords: Tourism in Brazil. International Tourism. Meta-analysis.

RESUMEN: El volumen de turistas internacionales creció un 68\% entre los años 2000 y 2014, según la OMT. Las ramificaciones de este crecimiento interesan tanto en el ámbito de los estudios de mercado como en el de los académicos. El objetivo general de este artículo es comprobar cómo figura Brasil en los estudios de publicaciones internacionales sobre turismo, utilizando como unidad de muestreo el Tourism Management. Esto hace que sea necesario discutir el papel del país en el interés investigativo de la producción internacional, ya sea como actor principal o como elemento de contextualización. La metodología utilizada en este estudio se centra en un meta-análisis sobre el contenido de las publicaciones en los artículos presentados, en base a las variables y técnicas de análisis de los estudios de Matos y Henrique (2006); Melo y Andreassi (2010); y Souza, Roglio y Takahashi (2011). El principal resultado de esta investigación es un indicador de que Brasil está aún poco explotado como objeto de estudio, y a menudo solo es citado en un contexto. Por último, en las consideraciones finales se analiza el papel de Brasil en el campo del Turismo y de la Administración, proponiendo algunos problemas de investigación para provocar el interés de los investigadores brasileños y extranjeros en asuntos en los que el país puede ser relevante para la investigación, aunque todavía esté sin explotar, especialmente en el campo de los estudios internacionales de turismo.

Palabras clave: Turismo en Brasil. Turismo internacional. Meta-análisis.

INTRODUÇÃO

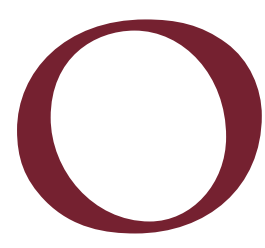

turismo internacional é compreendido pela Organização Mundial do Turismo (OMT) como atividades dos visitantes residentes fora do país de referência e as atividades de visitantes não residentes no país de referência, também chamado de turismo receptivo, que 
tem crescido constantemente nos últimos anos, subindo de 674 mil turistas em viagens internacionais no ano de 2000 para mais de 1 bilhão e cem milhões em 2014 (UNWTO, 2014). Segundo o relatório anual sobre o turismo internacional da OMT, em 2015 o volume de turistas internacional deve crescer de 3\% a 4\% em relação a 2014, contribuindo para a recuperação econômica global, que está em crise (UNWTO, 2014).

No Brasil o volume de turistas internacionais cresce em ritmo análogo ao fluxo de turistas no mundo. Os dados do Ministério do Turismo mostram que no ano de 2003 a quantidade de turistas estrangeiros em viagem ao Brasil foi de 52.489 (MT, 2005), enquanto em 2014 o volume somou 6.429.852 (MT, 2015) estrangeiros em visita ao Brasil, injetando milhões de dólares todos os anos na economia local, seja por meio da hotelaria, do comércio, ou da prestação de serviço diretamente ligada ao turismo.

Dada a relevância do setor de turismo para a economia mundial, muitos estudos são publicados periodicamente abordando questões sobre a gestão do turismo, do marketing, do investimento direto do capital estrangeiro, do empreendedorismo, dentre outras abordagens teóricas. Uma série de periódicos internacionais com excelente avaliação, segundo as métricas Qualis da Coordenação de Aperfeiçoamento de Pessoal de Nível Superior (CAPES), tem publicado frequentemente vários estudos sobre o setor de turismo no mundo, como o International Business Review, que publicou 58 artigos sobre turismo internacional de 1992 a 2014 (IBR, 2015); e o Journal of Business Research (JBR, 2015) teve 359 sobre turismo desde o ano de 1988; enquanto o periódico Tourism Management (TM, 2015) teve 4066 artigos sobre turismo desde o ano de 1982. Analisando apenas os dados desses três periódicos, tem-se uma média de 172 publicações sobre turismo internacional por ano.

Uma vez identificado o interesse científico internacional pela pesquisa sobre o turismo, é necessário então entender qual é o papel do Brasil dentro dessas pesquisas como objeto de estudo, seja como parte da construção teórica ou empírica. Apresenta-se como problema de pesquisa a seguinte questão de investigação: como o Brasil é estudado na produção científica internacional sobre turismo? 
Para buscar respostas ao problema de pesquisa, propõe-se o seguinte objetivo geral: analisar a produção científica sobre o turismo e o Brasil, a fim de mapear indicadores empírico, analítico e metodológico desses estudos. E por meio dessas publicações, discutir o papel do país no interesse investigativo na produção internacional.

Para tornar essa investigação exequível, desdobram-se os seguintes objetivos específicos:

- Mapear as publicações sobre turismo internacional identificando a natureza dos estudos, as teorias abordadas, as metodologias aplicadas, as regiões geográficas estudadas;

- Verificar se o Brasil é abordado como escopo principal das publicações analisadas;

- Discutir a importância das pesquisas que tiveram o Brasil como foco de estudo para o entendimento sobre o seu papel no turismo internacional;

- Propor problemas para serem pesquisados em estudos futuros.

Espera-se com este estudo oferecer um mapeamento sobre os interesses de pesquisa em turismo internacional abordando o Brasil, provocar novos problemas para estudos futuros e oferecer um modelo de meta-análise adaptado às características da pesquisa em Turismo Internacional, a fim de proporcionar um modelo analítico que possa ser explorado e ampliado por outros pesquisadores, contribuído com as pesquisas futuras.

\section{O TURISMO INTERNACIONAL COMO PROBLEMA DE PESQUISA}

O turismo é um fenômeno complexo e multi-inter-transdisciplinar (SCHNEIDER; SANTOS, 2013), tornando-se objeto de muitas definições e linhas de abordagem desde o início do século XX. O turismo é um setor privado e de negócios, que está relacionado ao fluxo de pessoas, à produção e ao consumo de uma grande variedade de produtos e serviços, tangíveis e intangíveis, causando impactos econômicos e sociais (SANTOS; SOUZA; PEREIRA, 2014), portanto está 
relacionado a diversos interesses da área de Administração, como marketing, estratégias, formação de redes, empreendedorismo, negócios internacionais, entre outros. Dessa forma se faz necessário pensar o turismo como um setor de interesse global.

A globalização da economia e as conexões entre pessoas, culturas e locais diminuem distâncias e favorecem a chamada indústria do turismo. "A atividade do turismo está ajudando a redesenhar as estruturas mundiais, influenciando a globalização, os novos blocos econômicos e a nova ordem mundial" (FREITAG; TISCOSKI; NETO, 2010, p. 2). O crescimento do fluxo de turistas no mundo e a abertura de países para receber a visita de consumidores de todas as partes do planeta não oferecem apenas uma oportunidade de crescimento econômico regional ou ampliação das atividades de negócios, não obstante, oferece também um terreno fértil de pesquisas no campo da Administração e dos Negócios Internacionais. Empresas são criadas, o consumo de produtos e serviços é ampliado, a economia aquece e uma série de desdobramentos, oriundos dessas atividades de consumo pelo mundo, deve ser investigada pela comunidade acadêmica, a fim de entender melhor como o fenômeno do turismo, sob as lentes da investigação científica, interferem nos negócios e na sociedade.

A diversidade de temas e de objetos de estudo no campo do turismo pelos pesquisadores de Administração ainda não é explorada em sua totalidade, pois os estudos sobre turismo, no Brasil e no mundo, referem-se basicamente a temas ligados ao impacto cultural e econômico, tendo a área de ciências econômicas mais interesse sobre o crescimento e a movimentação de riquezas a partir do setor de turismo (BARRETO, 2003). Questões, por exemplo, envolvendo áreas estratégicas das empresas como comunicação e marketing, ou alianças estratégicas entre parceiros de segmentos, como hotelaria, comércio e prestadores de serviços turísticos, ainda são pouco explorados, quando se olha para os objetos de estudos debatidos nos eventos ou periódicos de administração (FREITAG; TISCOSKI; NETO, 2010).

Pouco se sabe, por exemplo, como os turistas podem construir a imagem do destino turístico a partir do uso de mídias digitais, fomentando as suas redes de relacionamentos com as experiências vividas, quase que em tempo real, e o 
desdobramento dessas atividades promocionais na divulgação e na ampliação da promoção desses destinos de forma espontânea, muitas vezes sem custo algum para os setores prestadores de serviços e áreas que dependem do turismo, como a sua principal fonte de desenvolvimento econômico. Estudos sobre a imagem do destino turístico estão interligados com a imagem cognitiva, imagem afetiva e imagem global do local (HYUN; OKEEFE, 2012).

Outro ponto importante sobre as oportunidades que a investigação sobre o turismo pode oferecer ao campo da pesquisa em Administração é que não se pode voltar a atenção apenas para as questões de gestão das empresas prestadoras de serviços ou de comércio. É necessário entender também como o turista decide seu roteiro de viagem e quais as variáveis que interferem nesse processo de decisão, como alertaram Vieira e Hoffman (2013), quando afirmaram que os destinos turísticos estão ligados a um conjunto de produtos e serviços integrados, comercializados e consumidos pelos turistas; esses fatores apontam para a necessidade de que as pesquisas tenham uma visão mais ampla, que considerem variáveis que afetem direta ou indiretamente o desempenho da competitividade das empresas no setor de turismo, pelo destino que o turista toma como decisão. Os turistas não precisam mais de um agente de turismo para obter recomendações para decidir para onde visitar, a internet tornou possível ao turista reunir uma série de informações capazes de tornar a decisão cada vez mais autônoma, basta o turista navegar por sites de viagens, blogs, redes sociais, colher informações, depoimentos, roteiros, preços, entre outras inúmeras informações que facilitam a busca pelo local ideal (BATISDA; HUAN, 2014).

O que ajuda entender essas lacunas deixadas pelo campo da pesquisa científica sob a ótica do turismo pela Administração é o fato que em 2010, quando Freitag, Tiscoski e Neto publicaram seu estudo sobre a produção acadêmica sobre o turismo, tendo como objeto de estudo o EnANPAD, identificaram uma baixa frequência de publicações específicas sobre o tema, pois dos 54 artigos pesquisados, $85 \%$ tinham o conhecimento em turismo como um processo em construção. Reforçando a ideia de que o Turismo é mais pesquisado no campo mercadológico do que científico, dentro da área de Administração, Perez-Nebra e Torres (2010) alertaram que a maior parte das pesquisas sobre turismo dentro da América do Sul é oriunda de empresas privadas voltadas especialmente aos interesses internos dos negócios dessas empresas. 
A produção acadêmica em turismo no país "passa por um processo de construção e necessita de uma definição de padrões de qualidade a fim de alcançar níveis superiores de contribuição ao desenvolvimento do estado da arte deste campo de estudo" (FREITAG; TISCOSKI; NETO, 2010, p. 10). Assim, a discussão teórica e empírica sobre o turismo no Brasil e a internacionalização do turismo são um campo fértil para a academia, dada as implicações que a indústria do turismo tem na economia, na sociedade, nas empresas, na cultura e no meio ambiente.

\section{PROCEDIMENTOS METODOLÓGICOS}

Esta pesquisa é de natureza quantitativa, baseada nos métodos de metaanálise de conteúdo (MATOS; HENRIQUE, 2006; MELO; ANDREASSI, 2010; SOUZA; ROGLIO; TAKAHASHI, 2011), que objetivou analisar o perfil das publicações científicas que abordavam o Brasil no contexto do turismo internacional. A metaanálise é uma técnica cujo pesquisador interage com a produção acadêmica, por meio da identificação e quantificação dos dados, para que seja possível o mapeamento da produção científica por meio de variáveis estabelecidas para o estudo, verificando escolhas metodológicas e teóricas, aproximando ou diferenciando trabalhos entre si (NOGUEIRA; SETTE, 2013). Para esses autores, a meta-análise é mais do que uma revisão bibliográfica, é um estudo avançado sobre a produção científica que possibilita comparações e conclusões acerca do tema pesquisado.

Para isto, alguns critérios foram previamente definidos, a fim de se delimitar a amostra pesquisada. O objeto de estudo foi o Journal Tourism Management - TM, qualificado como A2 pela métrica Qualis (CAPES, 2015) de avaliação de periódicos científicos e pela especificidade em tratar de ser um periódico internacional de gestão do turismo. Levou-se em consideração o fator de impacto do periódico que teve o fator de 2.554, dado pelo Thomson Reuters Journal Citation Reports de 2015, com fator normalizado por artigo (SNIP): 2.643, SClmago Journal Rank (SJR): 2.111 e, o fator de impacto dos últimos cinco anos é de 3.762 (TM, 2015). O critério de seleção da amostra foi o de abrangência temporal de análise dos periódicos (TONELLI et al., 2003; TONELLI; 
CALDAS, 2004; MATOS; HENRIQUE, 2006; MELO; ANDREASSI, 2010; SOUZA; ROGLIO; TAKAHASHI, 2011). No período pesquisado o total de publicações do Tourism Management foi de 602 artigos entre 2005 e 2014, e inicialmente a amostra foi selecionada por meio da palavra-chave 'brazil' dentro do periódico, correspondendo inicialmente em 39 filtrados.

A seleção dos artigos que formam a amostra desse estudo se deu por julgamento, que se dá pela determinação de fatores que os autores julgam necessários e suficientes para responder ao problema de pesquisa (MALHOTRA, 2012; MATTAR, 2014; NIQUE; LADEIRA, 2014), nesse caso específico, artigos que tratem do turismo no âmbito internacional e que tenham o Brasil como país de estudo no processo da construção teórica ou empírica. O processo de leitura e coleta dos dados para análise se deu por meio de buscas da palavra-chave 'brazil' na ferramenta de busca do periódico, orientada pelos campos de título, resumo e palavras-chaves. Com isso 16 artigos foram retirados da amostra inicial, pois as únicas referências ao tema turismo correlacionando o país Brasil eram citações de outros autores, usadas apenas como forma comparativa na construção da narrativa do texto teórico, sem qualquer aprofundamento, por isso o descarte foi adotado, a fim de não contaminar negativamente o processo de análise com os trabalhos que se distanciariam muito do escopo original deste trabalho. Dessa forma, a amostra final é de 23 artigos publicados. Considerouse que esses artigos selecionados se apropriavam do Brasil como objeto (ou parte) de estudo para a construção da teoria ou da empiria.

Posteriormente à seleção destes artigos, procedeu-se à leitura dos seus resumos, problematização, metodologia, abordagem teórica, técnicas de análises e conclusões/considerações (NOGUEIRA; SETTE, 2013), para que os dados fossem coletados, organizados, tabulados e analisados, conforme a organização das variáveis propostas no Quadro 1.

Os dados analisados são secundários, coletados nas publicações selecionadas do IBR e dados da Organização Mundial do Turismo (OMT). As variáveis analisadas na meta-análise (Quadro 1) foram definidas por meio dos trabalhos de Matos e Henrique (2006); Melo e Andreassi (2010); e Souza, Roglio e Takahashi (2011), além de quatro outras propostas pelos autores deste artigo, com a finalidade 
de ajustar o modelo de análise ao tema proposto - turismo internacional, totalizando dez variáveis observadas.

Quadro 1. Variáveis utilizadas na meta-análise

\begin{tabular}{|c|c|}
\hline VARIÁVEIS & AUTORES \\
\hline Ano de publicação & $\begin{array}{c}\text { (NOGUEIRA; SETTE, 2013) } \\
\text { (MELO; ANDREASSI, 2010) }\end{array}$ \\
\hline Natureza (Quantitativa x Qualitativa) & $\begin{array}{c}\text { (SOUZA; ROGLIO;TAKAHASHI, 2011) } \\
\text { (NOGUEIRA; SETTE, 2013) } \\
\text { (MELO; ANDREASSI, 2010) }\end{array}$ \\
\hline Tipo (Teórico x Empírico) & $\begin{array}{c}\text { (NOGUEIRA; SETTE, 2013) } \\
\text { (SOUZA; ROGLIO;TAKAHASHI, 2011) }\end{array}$ \\
\hline Filiação dos autores & (NOGUEIRA; SETTE, 2013) \\
(MELO; ANDREASSI, 2010) \\
(SOUZA; ROGLIO;TAKAHASHI, 2011)
\end{tabular}

Fonte: Elaborado pelos autores.

As variáveis propostas para adequar o modelo de meta-análise para estudos sobre turismo visam criar uma delimitação, a fim de tornar mais específico esse modelo para a área de estudos em turismo internacional. A variável 'região/ país pesquisado' se faz necessária para que seja possível visualizar onde está localizado o interesse de pesquisa dos autores, de tal forma que esse dado possa ser comparado e/ou associado com outras variáveis como PIB, IDH, volume de turistas internacionais, entrada de capital estrangeiro no país, rankings de desenvolvimento econômico, entre outras possibilidades. Analogamente, a variável 'produtos/serviços ligados diretamente ao turismo' se faz necessária para entender o quanto os estudos estão ligados ao setor de turismo, ou se o turismo apenas aparece como um pano de fundo para uma discussão empírica ou teórica, pontual dentro do estudo. A variável 'parceria entre autores 
de diferentes países' busca verificar a formação de redes de parcerias entre autores estrangeiros, identificando o interesse comum sobre o mesmo objeto e a interação interinstitucional das publicações internacionais. Por fim, a variável 'volume de citações no Google Scholar' foi indicada para verificar a relevância da contribuição acadêmica desses estudos e o interesse que tem despertado em estudos posteriores, de outros autores, e com isso é possível entender se os estudos podem criar correntes teóricas ou empíricas, dado o seu impacto em outras publicações.

\section{META-ANÁLISE}

Uma vez identificados e selecionados os artigos para análise, a primeira observação em relação à distribuição das publicações de artigos por ano (Tabela 1) foi que mostrou ascendência no volume de publicações ao longo dos últimos dois anos. Em média foram publicados 2,3 artigos por ano no período de dez anos da amostra. Nos últimos dois anos (2013 a 2014), a média foi de 5,5 artigos publicados, o que mostra um interesse maior sobre o Brasil na área de gestão do turismo nas publicações mais recentes. Nesse mesmo período, segundo dados da Organização Mundial de Turismo (UNWTO, 2015), o fluxo de turistas cresceu mais de $15 \%$ no volume de turistas viajando pelo mundo, mostrando que o interesse de observar o Brasil caminha ao lado do crescimento do turismo mundial.

Tabela 1: Total de artigos filtrados pela palavra-chave 'brazil' e número de artigos selecionados para a amostra

\begin{tabular}{|c|c|c|c|c|}
\hline \multirow[t]{2}{*}{ Ano } & \multicolumn{2}{|c|}{ Total } & \multicolumn{2}{|c|}{ Artigos } \\
\hline & $\mathrm{N}^{\circ}$ & $\%$ & $\mathrm{~N}^{\circ}$ & $\%$ \\
\hline 2005 & 1 & 100 & 1 & 100 \\
\hline 2006 & 3 & 100 & 3 & 100 \\
\hline 2007 & 4 & 100 & 3 & 75 \\
\hline 2008 & 3 & 100 & 1 & 33,33 \\
\hline 2009 & 1 & 100 & 0 & 0 \\
\hline 2010 & 3 & 100 & 2 & 66,66 \\
\hline 2011 & 4 & 100 & 1 & 25 \\
\hline 2012 & 3 & 100 & 1 & 33,33 \\
\hline 2013 & 6 & 100 & 4 & 66,66 \\
\hline 2014 & 9 & 100 & 7 & 77,77 \\
\hline Total & 37 & 100 & 23 & 62,16 \\
\hline
\end{tabular}

Fonte: Autores, 2015. 
Dos 23 artigos pesquisados, descobriu-se que a origem dos autores das publicações está distribuída entre 17 países distintos, totalizando 32 autores que compõem o elenco das publicações (Tabela 2), dos quais os autores mais frequentes são da Espanha (12,5\%) e Austrália (15,68\%).

Tabela 2: Origem da filiação dos autores que publicaram os artigos

\begin{tabular}{ccc|ccc}
\hline Origem & \multicolumn{2}{c}{ Total } & \multicolumn{2}{c}{ Origem } & Total \\
África do Sul & $\mathbf{N}^{\circ}$ & $\mathbf{\%}$ & $\mathbf{N}^{\circ}$ & $\%$ \\
Austrália & 1 & 3,12 & Holanda & 1 & 3,12 \\
Brasil & 5 & 15,68 & Ilhas Maurício & 1 & 3,12 \\
Chile & 2 & 6,25 & Itália & 1 & 3,12 \\
China & 1 & 3,12 & Nova Zelândia & 1 & 3,12 \\
Emirados Árabes & 2 & 6,25 & Portugal & 2 & 6,25 \\
Espanha & 1 & 3,12 & Reino Unido & 3 & 9,37 \\
Estados Unidos & 4 & 12,5 & Suíça & 1 & 3,12 \\
Grécia & 3 & 9,37 & Taiwan & 2 & 6,25 \\
Total & 1 & 3,12 & & & \\
\hline
\end{tabular}

Fonte: Autores, 2015.

Como se trata de publicações internacionais, foi de interesse dessa pesquisa identificar se há colaboração entre países para desenvolver estudos sobre o turismo. Com isso, descobriu-se que 39\% das publicações foram feitas por autores de dois países diferentes (Gráfico 1), mostrando uma boa representatividade das parcerias entre instituições de países distintos para a cooperação da produção científica. 
Gráfico 1: Distribuição dos artigos mediante a ocorrência de parceria entre países

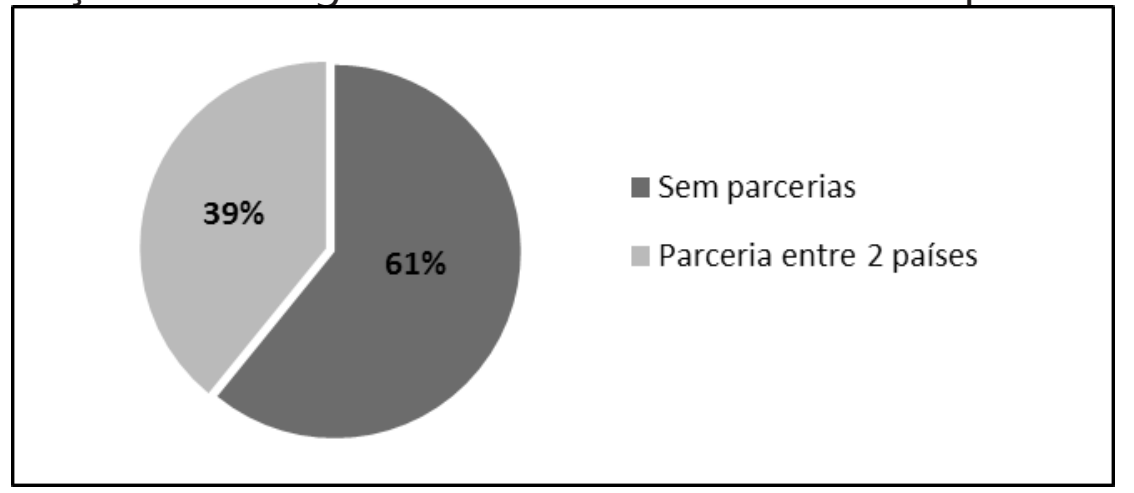

Fonte: Autores, 2015.

O perfil da amostra (Tabela 3) dos artigos tende para publicações de natureza quantitativa, que representa $73 \%$ do volume de artigos pesquisados, evidenciando (nessa amostra) uma predileção dos autores por mensuração e quantificação dos dados investigados. Apenas 6 artigos, dos 23, têm natureza qualitativa. Outra característica de destaque é que $91,3 \%$ dos artigos são de pesquisas empíricas. Já em relação aos artigos que tratam apenas de discussão teórica, a representatividade foi baixa, de apenas 8,7\%. Esse dado pode ser explicado dada a capacidade exploratória que o tema Turismo Internacional tem, mediante os dados de crescimento e impacto mundial.

Tabela 3: Distribuição de artigos mediante a natureza e o tipo

\begin{tabular}{cccccc}
\hline Natureza & \multicolumn{2}{c}{ Teórico } & \multicolumn{2}{c}{ Empírico } \\
& $\mathbf{N}^{\circ}$ & & $\%$ & $\mathbf{N}^{\circ}$ & $\%$ \\
Qualitativa & 2 & 8,7 & 4 & 17,4 \\
Quantitativa & 0 & 0 & 17 & 73,9 \\
Total & & & 23 & $\mathbf{1 0 0}$ \\
\hline
\end{tabular}

Fonte: Autores, 2015.

Ao verificar os tipos de dados coletados e analisados nas publicações, descobriu-se que a maior parte, $70 \%$, dos artigos é proveniente de dados secundários (Gráfico 2). Esse é um dado que mostra uma lacuna a ser preenchida por pesquisas provenientes de entrevistas, aplicação de questionários, grupos focais e demais pesquisas que visam ao entendimento do fenômeno por meio da observação direta. As pesquisas feitas apenas com dados secundários 
podem limitar o campo de investigação, pois nem sempre os dados são atuais, muitas vezes sofrem defasagem de anos. Os resultados ficam comprometidos e muitas vezes sugerem realidades que não satisfazem a sua contemporaneidade. É possível compreender que as pesquisas com dados primários estejam em menor número, possivelmente porque a aplicação de questionários e entrevistas leva mais tempo, normalmente custam mais e dependem da disponibilidade dos pesquisados na cooperação do levantamento dos dados, tornando assim a pesquisa com dados secundários mais rápida e conveniente.

Gráfico 2: Distribuição dos artigos mediante o tipo de dado coletado e analisado

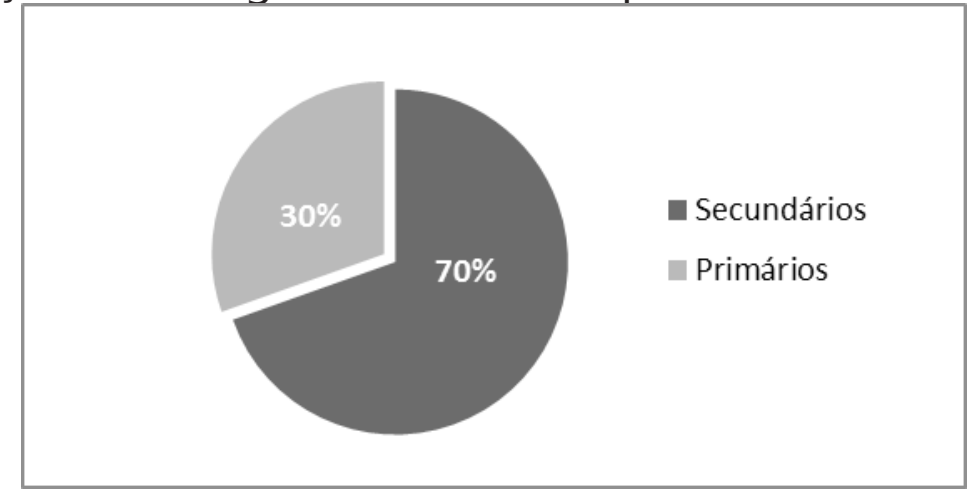

Fonte: Autores, 2015.

Ainda dentro das características metodológicas dos artigos, pontuam-se quais são os métodos de análises mais frequentes nos artigos pesquisados, a fim de mostrar tendências de análises mediante as pesquisas apresentadas. O método de análise mais frequente foi o de Equações Estruturadas (SEM), figurando em 23,7\% dos artigos pesquisados, seguido do estudo de caso, frequente em 20,51\% dos estudos. Revisão bibliográfica e ANOVA foram os métodos de análise dos artigos menos frequentes. A revisão bibliográfica apenas apareceu como método analítico em apenas 2 artigos, justamente os qualitativos teóricos. Nota-se a tendência dos métodos quantitativos nas pesquisas em turismo. 
Gráfico 3: Distribuição dos artigos mediante o tipo de dado coletado e analisado

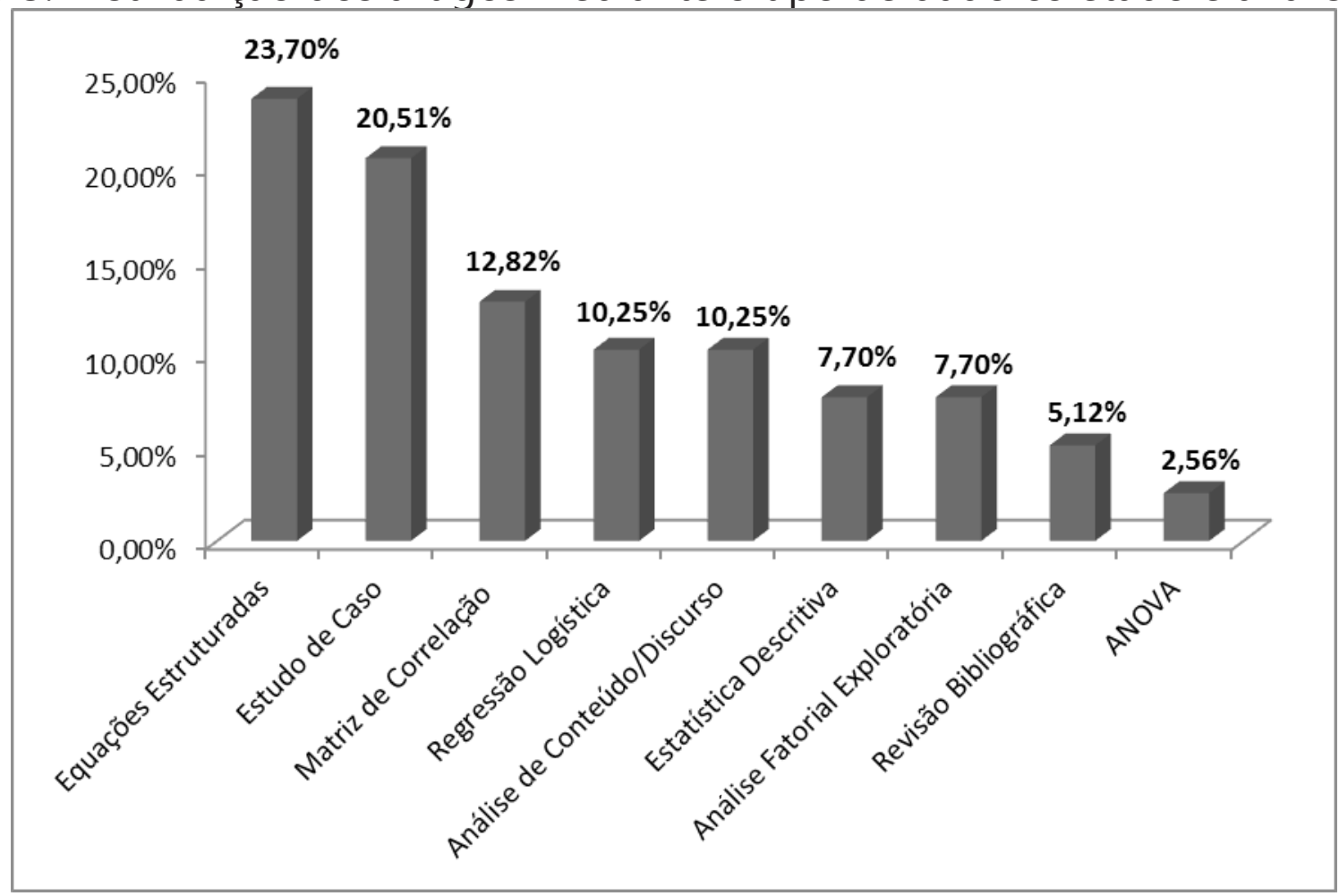

Fonte: Autores, 2015.

Outra variável importante no estudo de turismo internacional é a identificação de qual país ou região é o foco dos estudos, pois o entendimento sobre quais são os países que mais são pesquisados pode oferecer importantes cruzamentos de informações, por exemplo, se o interesse de pesquisa está ligado aos países emergentes, ou a distância psíquica entre os países. Ao analisar a amostra de artigos, identificou-se que 24 países aparecem como objeto de estudo das pesquisas analisadas (Tabela 4). O Brasil, apesar de aparecer em todos os artigos, muitas vezes figura como suporte teórico oriundo de outras pesquisas e como exemplo para reforçar uma proposição do autor, não necessariamente ele fez parte da empiria. Em apenas um dos artigos o Brasil foi objeto único e principal do estudo, nos demais ele era uma das partes. Ainda com relação aos países que figuraram com maior frequência nos estudos dos artigos pesquisados, temse Austrália, China, Argentina, Canadá, Chile, Espanha, França e Nova Zelândia, como os países mais representativos junto do Brasil nessa meta-análise. 
Tabela 4: Frequência de vezes em que os países figuram como objeto de estudo nos artigos pesquisados

\begin{tabular}{|cc|cc|cc|}
\hline País & Frequência & País & Frequência & País & Frequência \\
Argentina & 4 & Coreia & 2 & Japão & 2 \\
Áustria & 3 & Espanha & 4 & México & 2 \\
Austrália & 5 & Estados Unidos & 3 & Nova Zelândia & 4 \\
Brasil & 6 & França & 4 & Peru & 2 \\
Canadá & 4 & Grécia & 2 & Portugal & 3 \\
Caribe & 2 & Hong Kong & 2 & Reino Unido & 3 \\
Chile & 4 & Indonésia & 2 & República & 2 \\
China & 5 & Itália & 2 & Urugua & 2 \\
\hline
\end{tabular}

Fonte: Autores, 2015.

Para analisar a variável 'produtos/serviços turísticos' nos artigos pesquisados, a identificação desses produtos e serviços se deu pelas dez dimensões do turismo, citadas por Perez-Nebra e Torres (2010): alojamento; provisão de alimentação e bebidas; transporte de passageiros; agência de viagem, operadoras e guias de turismo; serviços culturais; recreativos e lazer; comércio; cenário; cordialidade da população local; diversos. Acrescenta-se a esses elementos o item 'Não identificado', para os artigos que não tratarem de algum tipo de produto e/ou serviço turístico. Ao analisar e enquadrar os artigos dentro dessas categorias, descobriu-se que em nenhum dos artigos questões ligadas às agências de viagens, comportamento da população receptiva ou provisão de alimentos e bebidas foram estudas, tendo como foco maior alojamento (em estudos voltados para setor hoteleiro), serviços culturais (Gráfico 4). 
Gráfico 4: Frequência de pesquisas das principais dimensões do turismo internacional

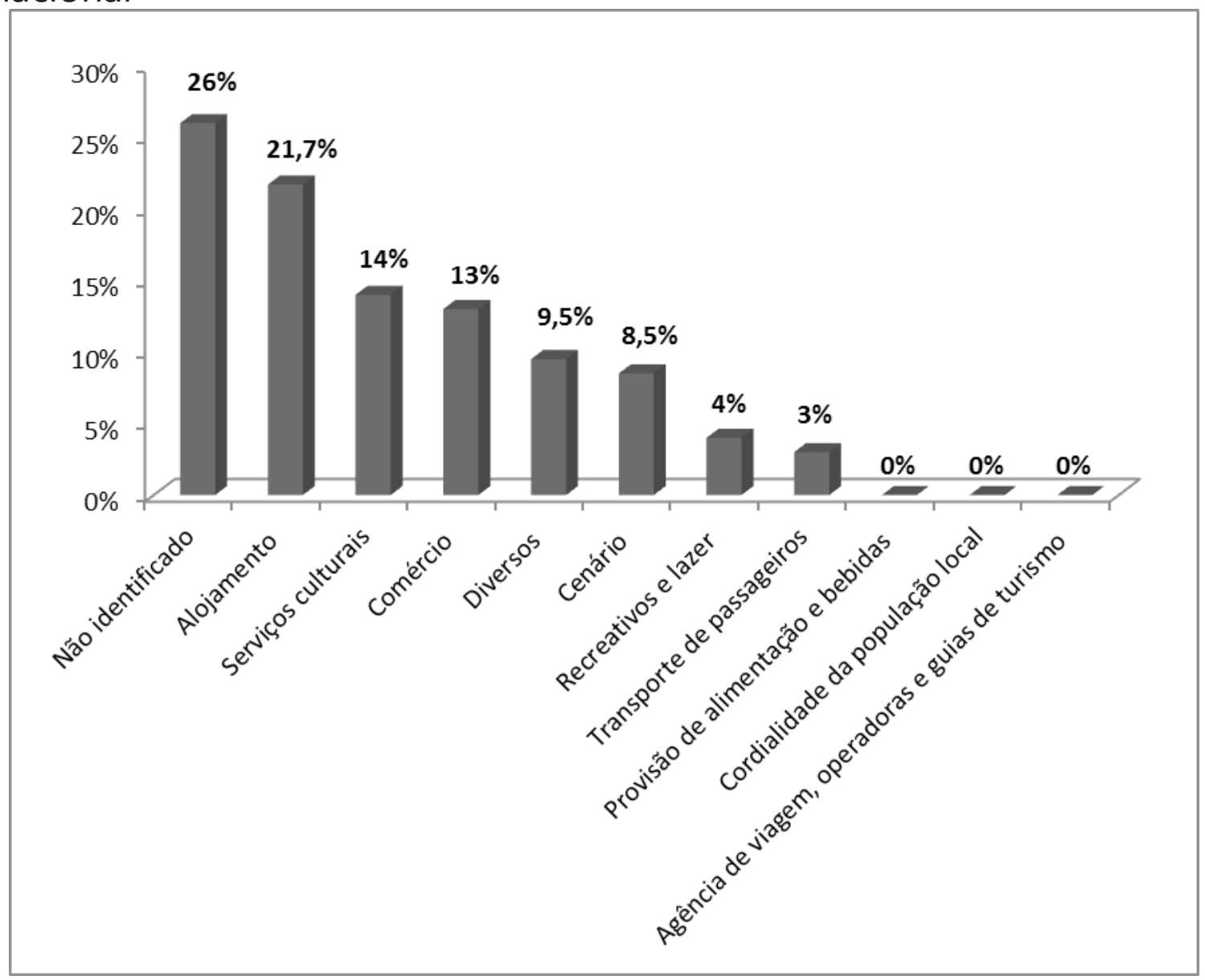

Fonte: Autores, 2015.

Ainda não há um equilíbrio na diversidade de assuntos pesquisados, o que mostra uma lacuna a ser preenchida com pesquisas futuras, especialmente relacionadas às dimensões do turismo, como: o transporte de passageiros, agências de viagens, receptivas locais, e a imagem do país visitado. Os artigos pesquisados também mostraram baixa adesão no campo da administração, tendo a maior parte das abordagens voltadas para economia, ciências sociais e biodiversidade.

Finalizando a análise dos dados obtidos por meio da meta-análise, apresenta-se o impacto de citações gerado pelos artigos da amostra. Aqui estão elencados os dez artigos com h-index de maior volume (Tabela 5). Dessa forma é possível ver quais os assuntos pesquisados geraram maior interesse de outros pesquisadores, evidenciando a significância da contribuição acadêmica de cada um dos trabalhos listados. 
Tabela 5: Ranking com os dez artigos mais citados pelo Google Acadêmico

\begin{tabular}{|c|c|c|c|}
\hline AUTOR(ES) & TÍTULO DO ARTIGO & ANO & $\mathrm{H}^{*}$ \\
\hline $\begin{array}{c}\text { Richards, G.; Wilson, } \\
\text { J. }\end{array}$ & $\begin{array}{l}\text { Developing creativity in tourist experiences: A solution to the } \\
\text { serial reproduction of culture? }\end{array}$ & 2006 & 498 \\
\hline Hunter, C.; Shaw, J. & The ecological footprint as a key indicator of sustainable tourism & 2007 & 211 \\
\hline $\begin{array}{l}\text { Khadaroo, J.; } \\
\text { Seetanah, B. }\end{array}$ & $\begin{array}{l}\text { The role of transport infrastructure in international tourism } \\
\text { development: A gravity model approach }\end{array}$ & 2008 & 183 \\
\hline Croes, R. R. & $\begin{array}{l}\text { A paradigm shift to a new strategy for small island economies: } \\
\text { Embracing demand side economics for value enhancement and } \\
\text { long term economic stability }\end{array}$ & 2006 & 123 \\
\hline $\begin{array}{l}\text { Funk, D. C.; Bruun, } \\
\text { T. J. }\end{array}$ & $\begin{array}{l}\text { The role of socio-psychological and culture-education motives } \\
\text { in marketing international sport tourism: A cross-cultural } \\
\text { perspective }\end{array}$ & 2007 & 119 \\
\hline Endo, $\mathrm{K}$. & Foreign direct investment in tourism—flows and volumes & 2006 & 93 \\
\hline $\begin{array}{l}\text { Schianetz, K.; } \\
\text { Kavanagh, L.; } \\
\text { Lockington, D. }\end{array}$ & $\begin{array}{l}\text { The Learning Tourism Destination: The potential of a learning } \\
\text { organisation approach for improving the sustainability of tourism } \\
\text { destinations }\end{array}$ & 2007 & 92 \\
\hline $\begin{array}{l}\text { García, J. A.; Goméz, } \\
\text { M.; Molina, A. }\end{array}$ & $\begin{array}{l}\text { A destination-branding model: An empirical analysis based on } \\
\text { stakeholders }\end{array}$ & 2012 & 72 \\
\hline $\begin{array}{l}\text { Croes, R. R.; } \\
\text { Vanegas, M. }\end{array}$ & $\begin{array}{l}\text { An econometric study of tourist arrivals in Aruba and its } \\
\text { implications }\end{array}$ & 2005 & 67 \\
\hline $\begin{array}{c}\text { Carnicelli-Filho, S.; } \\
\text { Schwartz, G. M.; } \\
\text { Tahara, A. K. }\end{array}$ & Fear and adventure tourism in Brazil & 2010 & 36 \\
\hline
\end{tabular}

Fonte: Autores, 2015.

* Valor do H-index gerado pelo software Publish or Perish

\section{CONCLUSÕES E DESDOBRAMENTOS}

A partir da aplicação da meta-análise, notou-se que a principal contribuição deste artigo está no mapeamento dos aspectos metodológicos e analíticos que estão presentes nas pesquisas sobre turismo no âmbito internacional, tendo o Brasil como parte integrante dos estudos analisados.

Apesar de o Brasil aparecer nas buscas dos artigos, seja pelo resumo, palavras-chave ou título, ele não aparece com frequência como objeto de estudo principal. Quando se olha para os dados das autorias dos artigos, também é perceptível uma defasagem da produção nacional, pois apenas dois de trinta e dois autores são brasileiros. Esse dado merece reflexão, pois é 
possível questionar se não há produção e divulgação da produção nacional em periódicos internacionais abordando justamente o país de origem; é aceitável que esse país não seja um objeto de estudo tão relevante. Ficou evidenciado que o Brasil é pouco explorado no campo do turismo internacional, tanto por pesquisadores nacionais, quanto por pesquisadores internacionais, tendo a segunda categoria maior frequência de interesse de investigação com relação a esse país sul-americano.

Outro dado importante a ser destacado nessas conclusões finais é que, mesmo tendo a maioria dos artigos de caráter empírico, o Brasil aparece na maioria das vezes como citação, ou para contextualizar a introdução dos trabalhos, ou para o referencial teórico. Não há coleta de dados primários, como aplicação de entrevistas, grupos focais ou questionários, para análises quantitativas ou qualitativas de experimentos no país.

Carece dos pesquisadores maior interesse e empenho nas pesquisas sobre turismo no Brasil, sob perspectivas ligadas ao campo da Administração, sobretudo no que tange à internacionalização do turismo no país. Conhece-se pouco do país e das práticas que sustentam o setor do turismo (no campo da Administração e dos Negócios Internacionais), seja dentro da comunicação e do marketing que trabalham a imagem do país, seja por seus empreendedores, ou seja pelas políticas de incentivo e apoio do governo e da iniciativa privada em alavancar esse setor da economia.

O turismo no mundo, além de crescente, está ligado a uma profusão de fatores que devem ser pesquisados, que vai desde o gerenciamento da marca país, ao investimento direto estrangeiro dentro de empresas ligadas ao turismo, passando por questões de comunicação e marketing, empreendedorismo, políticas governamentais, globalização e negócios internacionais. Como disse Perez-Nebra e Torres (2010), o turismo é um negócio privado, porém ligado ao país, à cultura, à imagem. No campo do turismo internacional, especialmente no Brasil, é preciso voltar os olhares investigativos para a construção da imagem desse país, e como essa imagem reverbera no consumo de produtos e serviços e nas estratégias mercadológicas e políticas para a promoção turística, por exemplo.

O Brasil, como muitos países, quando analisado da perspectiva do turismo, está carregado de estereótipos que criam a sua imagem no mundo. A imprensa 
internacional apresenta o Brasil para o mundo, na maior parte das vezes, como uma nação que oscila do paraíso ao inferno, destacando as belezas naturais, a violência, a miséria e o turismo sexual (PAGANOTTI, 2007). Em um levantamento de 1.244 textos publicados em veículos internacionais, Paganotti (2007) identificou os principais estereótipos das narrativas que constroem a imagem do Brasil na imprensa internacional; e dentre os estereótipos da propaganda, que vende a imagem do país ao exterior, estão ligados elementos associados à sensualidade, à beleza natural, ao samba, ao carnaval, ao futebol, à cordialidade e à dramaticidade (das novelas). De certa forma, esses estereótipos são conhecidos de todos, inclusive dos mais leigos, o que limita a exploração da imagem de um país maior, mais diversificado e atraente.

Finalmente, isso provoca alguns questionamentos: qual o papel da Serra Gaúcha nos estereótipos do turismo internacional do Brasil? Gramado, com sua arquitetura baseada na influência da colonização alemã e italiana, se encaixa dentro do complexo de elementos samba-mulata-futebol, e como isso influencia a decisão do consumidor? Nesse sentido, esses estereótipos não só limitam a visão ampla de Brasil, como dificultam ações publicitárias e de marketing para mostrar algo que não é rotineiramente explorado. Um Brasil diferente do que se vê.

O turismo é um bem de consumo predominantemente abstrato (intangível) e é apresentado aos consumidores potenciais por meio de descrições, narrações, mídia e fotos (PEREZ-NEBRA; TORRES, 2010). O fato de a visita ao Brasil modificar a imagem que se tem do país (PEREZ-NEBRA; TORRES, 2010) é de grande relevância para a gestão do turismo, pois se a imagem aguça os sentidos, modela a imaginação e mitifica pessoas e localidades, então ela é o principal mecanismo motivacional de um atrativo turístico (CAETANO, 2004).

Com o apontamento dessas lacunas no campo da internacionalização do turismo no Brasil, propõe-se como desdobramentos dessa pesquisa o aprofundamento dos estudos com os seguintes possíveis problemas de investigação:

- Como países emergentes como o Brasil expandem o turismo em nível global? 
- As redes de cooperação entre o trade de turismo local e o trade de turismo de outros países podem alavancar o consumo turístico de ambas as partes?

- Como os negócios internacionais, por meio de feiras e eventos, afetam o crescimento do turismo em países emergentes como o Brasil?

- O crescimento do turismo internacional gera interesse de empresas multinacionais do entretenimento a expandirem suas unidades em países emergentes?

- Qual o impacto da distância psíquica no consumo de turismo internacional por brasileiros?

O Brasil oferece importantes objetos para serem estudados, dada a sua diversidade territorial, cultural e natural. Turismo Rural, Ecoturismo, Turismo Histórico, Turismo de Eventos são alguns dos objetos que podem ampliar a discussão sobre o debate da internacionalização do turismo no Brasil. Sendo o turismo essencialmente um negócio baseado em serviços, é primordial que a investigação em administração preencha essas lacunas e avance no entendimento desse fenômeno crescente e importante para a economia local e global.

Esse trabalho se encerra com várias provocações acerca do debate da investigação sobre turismo, tendo o Brasil como objeto de estudo no campo internacional. Mesmo com as limitações epistemológicas e empíricas, seja pelo tamanho da amostra ou pela captação dos dados ter se baseado em apenas um periódico internacional, fica aqui a provocação da necessidade de ampliar esse estudo para entender melhor os rumos e os indicadores das pesquisas sobre turismo internacional e o papel do Brasil nessas investigações, especialmente aquelas que fogem dos tradicionais temas: carnaval, sexo, samba e futebol, que ainda protagonizam os estudos internacionais. O Brasil necessita ser conhecido e reconhecido como um país maior do que o Rio de Janeiro, o litoral Nordestino e a Floresta Amazônica. 
BARRETO, M. (2003). O imprescindível aporte das ciências sociais para o planejamento e a compreensão do turismo. Horizontes Antropológicos. Porto Alegre, ano 9, n. 20, p.1529.

BATISDA, U.; HUAN, T. C. (2014). Performance evaluation of tourism websites' information quality of four global destination brands: Beijing, Hong Kong, Shanghai, and Taipei. Journal of Business Research, 67, p. 167-170.

CAETANO, R. (2004). A publicidade e a imagem do produto Brasil e da mulher brasileira como atrativo turístico. In: Congresso Brasileiro de Ciências da Comunicação, 27. Porto Alegre: INTERCOM, 2004, p.1-14.

FORTANIER, F.; WIJK, V. (2010). Sustainable tourism industry development in sub-Saharan Africa: Consequences of foreign hotels for local employment. International Business Review, 19, p. 191-205.

FREITAG, B. B.; TISCOSKI, G. P.; NETO, L. M. (2010). Análise da Produção Acadêmica em Administração sobre Turismo. 34. EnANPAD, Rio de Janeiro, 2010, p. 1-13.

HYUN, M. Y.; OKEEFE, R. M. (2012). Virtual destination image: Testing a telepresence model. Journal of Business Research, 65, p. 29-35.

MALHOTRA, N. K. Pesquisa de marketing: uma orientação aplicada. 6. ed. Porto Alegre: Bookman, 2012.

MATOS, C. A.; HENRIQUE, J. L. (2006). Balanço do Conhecimento em Marketing: uma Meta-Análise dos Resultados Empíricos dos Antecedentes e Consequentes da Satisfação e Lealdade. In: XXX EnANPAD, Salvador, p. 1-16.

MATTAR, F. N. Pesquisa de marketing: metodologia, planejamento, execução e análise. 7. Ed. Rio de Janeiro: Elsevier, 2014.

MELO, L. R.; ANDREASSI, T. (2010). Publicação Científica Nacional e Internacional sobre Franchising: Levantamento e Análise do Período 1998 - 2007. RAC, Curitiba, v. 14, n. 2, art. 5, p. 268-288.

MT. Anuário estatístico de turismo: 2014. Secretaria Nacional de Políticas de Turismo, v. 42, p. 1-131, 2015. Disponível em:<http://www.dadosefatos.turismo.gov.br/export/ sites/ default/dadosefatos/anuario/downloads_anuario/Anuario_Estatistico_de_Turismo_2015_-_ Ano_base_2014_-_Pdf.pdf>. Acesso em: 10 jul. 2015. 
MT. Anuário estatístico Embratur: 2005. Secretaria Nacional de Políticas de Turismo, v. 32, p. 1-236, 2005. Disponível em:<http://www.dadosefatos.turismo. gov.br/export/sites/default/ dadosefatos/anuario/downloads_anuario/anuario_2005_agencia__4_versao_x08_03_07x. pdf>. Acesso em: 10 jul. 2015.

NIQUE, W.; LADEIRA, W. Pesquisa de marketing: uma orientação para o mercado brasileiro. São Paulo: Atlas, 2014.

NOGUEIRA, C. M.; SETTE, R. S. (2013). Posicionamento em Marketing: Produção acadêmica Brasileira sob a ótica da Meta-Análise. In: IV EnEPQ. Brasília, p.1-15.

PAGANOTTI, I. (2007). Imagens e estereótipos do Brasil em reportagens de correspondentes internacionais. Rumores, São Paulo, v.1, p. 1-15.

PEREZ-NEBRA, A.R.; TORRES, C. V. (2010). Medindo a imagem do destino turístico: uma pesquisa baseada na teoria de resposta ao item. RAC, Curitiba, v. 14 , n. 1 , art. 5, p. 80-99.

SANTOS, T. S.; SOUZA, P. A. R.; PEREIRA, R. S. (2014). Pesquisa em turismo e desenvolvimento regional: análise dos estudos realizados no Brasil entre os anos de 1997 e 2013. In: XVII SEMEAD, São Paulo, p. 1-14.

SCHNEIDER, M.; SANTOS, M. C. (2013). Buscando construir um quadro teórico de referência para análise da hospitalidade em romarias. Revista Rosa dos Ventos, 5(4), p. 577-591.

SOUZA, C.; ROGLIO, K. D.; TAKAHASHI, A. R. W. (2011). Meta-análise da Produção Acadêmica em Gestão de Pessoas no Brasil (2001-2010). In: EnGPR, João Pessoa, p. 1-17.

TM. Tourism Management. Disponível em: < http://www.journals.elsevier.com/ tourism-management/> . Acesso em: 10 jun. 2015.

TONELLI, M. J; CALDAS, M. P. (2004). Produção acadêmica em recursos humanos na década de 90: uma análise metateórica da pesquisa brasileira em periódicos e nos anais do EnANPAD. FGV-EAESP/GVPESQUISA. São Paulo, p. 1-16.

TONELLI, M. J et al. (2003). Produção acadêmica em recursos humanos no Brasil: 
1991-2000. Revista de Administração de Empresas, 43 (1), p. 105-122.

UNWTO. Glossary of tourism terms. Madrid - Spain, 2014. Disponível em: < https://s3-eu-west-1.amazonaws.com/staticunwto/Statistics/ Glossary+of+terms.pdf>. Acesso em: 25 maio 2015.

UNWTO. Annual report 2014. Madrid - Spain, 2015. Disponível em:< http:// dtxtq4w60xqpw.cloudfront.net/sites/all/files/pdf/unwto_annual_report_2014. pdf. Acesso em: 25 maio 2015.

VIEIRA, D. P. HOFFMANN, V. E. (2013). Competitividade e Desenvolvimento: um estudo em Destinos Indutores do Turismo Brasileiro. II Encontro de Estudos em Estratégia. Bento Gonçalves, RS, p. 1-16. 